\title{
INCREASING THE VOLTAGE DROOP COMPENSATION RANGE IN GENERALIZED BIPOLAR SOLID-STATE MARX MODULADOR *
}

\author{
H. Canacsinh ${ }^{1,3, \xi}$, F. A. Silva ${ }^{2,3}$, L. M. Redondo ${ }^{1}$, P. Botelho ${ }^{1}$ \\ ${ }^{I}$ Instituto Superior de Engenharia de Lisboa, GIAAPP, Instituto Politécnico de Lisboa, Portugal \\ ${ }^{2}$ Instituto Superior Técnico, Universidade de Lisboa, Portugal \\ ${ }^{3}$ INESC-ID, Portugal
}

\section{Abstract}

This paper proposes solutions to increase the range of the voltage droop compensation needed to generate long pulses in the generalized solid-state Marx modulator. A novel design method based on the use of resonant circuits in generalized bipolar solid-state Marx modulator is described and evaluated. The increase of the compensation range is obtained by adding an extra auxiliary resonant stage to the existing Marx stages without changing the modularity of the circuit. The compensation is obtained by synchronously adding the voltages of the auxiliary compensation stages to the output voltage. Simulation results are presented for eight stages Marx circuit, $\sim 17 \%$ voltage droop, using $6 \mathrm{kV}$ bipolar pulses, $100 \mu$ s pulse duration and $50 \mathrm{~Hz}$ repetition frequency.

\section{INTRODUCTION}

Marx generators, also known as switched capacitor voltage multipliers [1], are one of the most used topology to generate high-voltage unipolar or bipolar pulses. Modern Marx generator use semiconductors to, charge $n$ capacitors in parallel, from a d.c. power supply, which are connected in series with a load, afterwards. Current Marx generators allow high pulse repetition rate, duty cycle adjustment and capability of dealing with different types of loads [2].

Among various characteristics of the solid-state Marx modulators, the flatness of the output voltage is an issue for applications such as food industry that requires high energetic long pulses (i.e. dozens of microseconds), as the capacitors voltage droops. Several authors have presented different droop corrections [3, 4] for unipolar Marx type circuits [5-7], based on auxiliary stages or "bouncer" circuits. In [8] a resonant type voltage droop compensation method has been developed for a solid-state bipolar Marx modulator. However, the proposed compensation method in [8] is a compromise between pulse repetition rate and resonant frequency. Another aspect is that the droop compensation percentage is inversely proportional with the number of Marx stages and limited by the power supply voltage.

This paper presents the preliminary results of a novel design method to increase the voltage droop compensation range for a solid-state bipolar Marx modulator shown in Fig. 1, whose operation was described in detail elsewhere $[9,10]$.

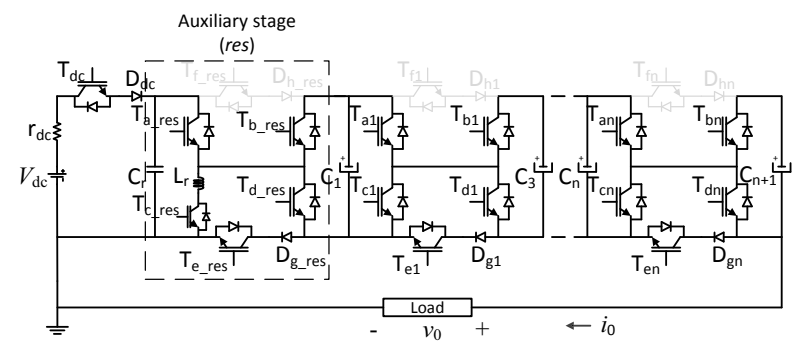

Figure 1. Generalized bipolar solid-state Marx modulator with $n$ stages for bipolar/unipolar pulse generation with voltage droop compensation (one stage) based on resonant circuit.

\section{CIRCUIT OPERATION}

Considering the circuit of Fig. 1, to increase the voltage droop compensation of the bipolar pulse, one extra auxiliary stage (res aux) was added after the $n^{\text {th }}$ Marx stage, as shown in Fig. 2.

This second voltage droop compensation stage differs from the first (res) auxiliary voltage droop compensation stage in the inductor location, as in the res stage it is located before the switch $\mathrm{T}_{\mathrm{c} \text { res }}$ and in the res_aux stage the inductor is located before the switch $T_{d}$ res aux

The circuit operation can be described in five steps: 1) capacitors charging; 2) resonance process before the positive pulse; 3 ) resonance process before the negative pulse; 4) positive pulse generation with droop

\footnotetext{
* This work was supported by national funds through Fundação para a Ciência e a Tecnologia (FCT) with reference UID/CEC/50021/2013, and through Instituto Politécnico Lisboa (IPL) with reference MBOCDTI/710046/2016.

$\xi$ email: hic@deea.isel.ipl.pt
} 
compensation; and 5) negative pulse generation with droop compensation.

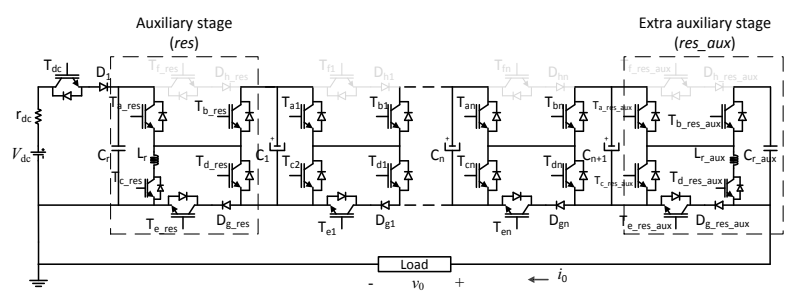

Figure 2. Generalized bipolar solid-state Marx modulator of Fig. 1 with increased voltage droop compensation range.

Considering the first step, in the charging process the capacitors $\mathrm{C}_{\mathrm{r}}, \mathrm{C}_{\mathrm{i}}$ and $\mathrm{C}_{\mathrm{r}_{-} \text {aux }}$ are charged by the dc power supply through switches $\mathrm{T}_{\mathrm{dc}}, \mathrm{T}_{\mathrm{a} \_ \text {res }}, \mathrm{T}_{\mathrm{a} i}, \mathrm{~T}_{\mathrm{a} \_ \text {res_aux }}, \mathrm{T}_{\mathrm{e} \_ \text {res_aux }}$, $\mathrm{T}_{\mathrm{ei}}$ and $\mathrm{T}_{\mathrm{e} \text { res }}$ driven $\mathrm{ON}$, as shown in Fig. 3. During this operating mode, the load voltage is negligible regarding the high output voltage.

Step two consists on starting the resonance process in the compensation stages res and res_aux. This is a necessary condition to generate high voltage pulses with droop compensation. The resonance process can be started by switching $\mathrm{ON}$ switches $\mathrm{T}_{\mathrm{a}_{-} \text {res }}$ and $\mathrm{T}_{\mathrm{c}_{-} \text {res }}$ (Fig. 3 a) and b)) for stage res and switches $\bar{T}_{b_{-} \text {res_aux }}$ and $T_{d_{-} \text {res_aux }}$ (Fig. 3 c) and d)) for stage res_aux, respectively, as shown in Fig. 3 1).

Considering Fig. 3, and for the negative pulse, the resonance process in the compensation stage res must obey a delay condition (1) with reference of the resonance process of stage res_aux,

$$
t=\frac{\pi}{\omega_{0}}
$$

where $t$ represents the delay time and $\omega_{0}$ the resonance frequency of each resonant compensation stage. Under these conditions, when the waveforms of the voltages in the capacitors $\mathrm{C}_{\mathrm{r}}$ and $\mathrm{C}_{\mathrm{r} \text { aux }}$ crosses the abscissas axis, a negative pulse with voltage droop compensation (step three) can be generated by triggering $\mathrm{ON}$ the switches $\mathrm{T}_{\mathrm{bi}}$ and $\mathrm{T}_{\mathrm{ci}}$ (Fig. $3 \mathrm{f}$ ) and g)) of stages $i=\{1,2, \ldots n\}$, as shown in Fig. 3 1)

During this process, there is a constraint regarding the turn OFF instant of switches $\mathrm{T}_{\mathrm{a} \_ \text {res }}$ and $\mathrm{T}_{\mathrm{c}_{-} \text {res }}($ Fig. $3 \mathrm{a}$ ) and b)) in stage res, as this can only occur between the interval of $\pi$ and $2 \pi$ of the resonance period of the res stage, to assure the continuity of the current and the recovery the energy in inductor $\mathrm{L}_{\mathrm{r}}$ back to the capacitor $\mathrm{C}_{\mathrm{r}}$. Regarding the res_aux stage, switches $\mathrm{T}_{\mathrm{b} \_ \text {res_aux }}$ and $T_{d_{-} \text {res_aux }}($ Fig. $3 \mathrm{c}$ ) and d)) can be turned off after the negative pulse without particular constraint.

Similarly, in step four, resonance for positive pulse before their generation, it is necessary to start the

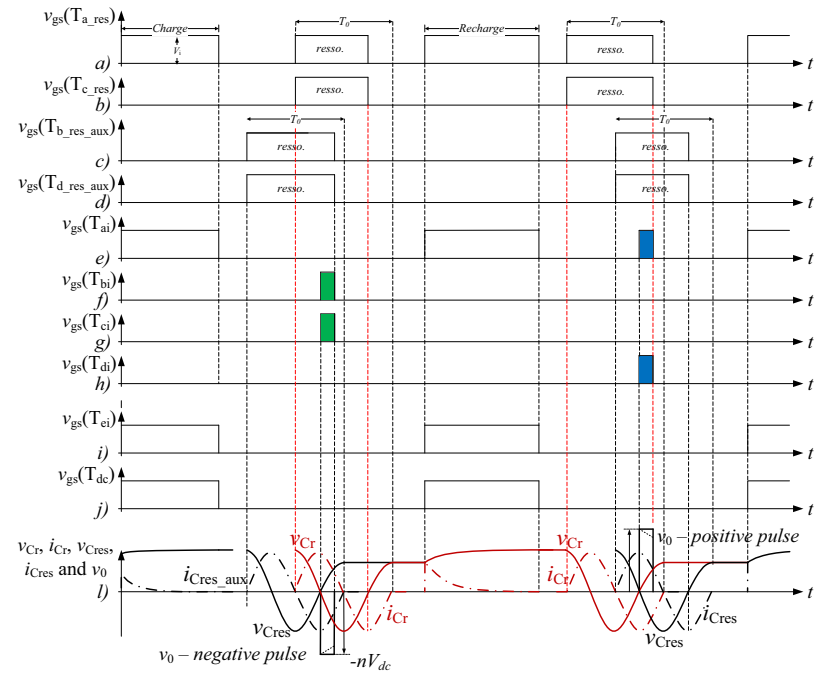

Figure 3. Theoretical waveforms for the operation of the solid-state Marx modulator of Fig. 2, considering a resistive load. Drive signal of semiconductors: a) $\mathrm{T}_{\mathrm{a}}$ res; $\mathrm{b}$ ) $\mathrm{T}_{\mathrm{c} \_ \text {res }}$; c) $\mathrm{T}_{\mathrm{b} \text { res_aux }}$; d) $\mathrm{T}_{\mathrm{d} \text { res_aux }}$; e) $\mathrm{T}_{\mathrm{ai}}$; f) $\mathrm{T}_{\mathrm{bi}}$; g) $\mathrm{T}_{\mathrm{ci}}$; h) $\mathrm{T}_{\mathrm{di}}$; i) $\mathrm{T}_{\mathrm{ei}}$; f) $\mathrm{T}_{\mathrm{dc}}$, l) $v_{\mathrm{Cr}}, i_{\mathrm{Cr}}, v_{\mathrm{Cres}}, i_{\text {Cres }}$ and output $v_{0}$ voltage.

resonance processes in the compensation stages res and res_aux, but in the reverse order regarding the negative pulse. Thus, the first stage to start the resonance process is the res stage and only after the delay condition (Eq. (1)), the resonance in stage res_aux can be started. Within this condition and when the waveforms of voltages in capacitors $\mathrm{C}_{\mathrm{r}}$ and $\mathrm{C}_{\mathrm{r}}$ aux passes through the zero, switches $\mathrm{T}_{\mathrm{ai}}$ and $\mathrm{T}_{\mathrm{di}}$ (Fig. $3 \mathrm{e}$ ) and $\mathrm{h}$ )) with $i=\{1,2, \ldots, n\}$ are turned $\mathrm{ON}$ (step five) to generate the positive pulse with compensation, as shown in Fig. 3 1).

Under this situation and after the positive pulse, the turn OFF of the switches $T_{b_{-} \text {res_aux }}$ and $T_{d_{-} \text {res_aux }}$ (Fig. $3 \mathrm{c}$ ) and d)) of the res_aux stage has to respect the interval between $\pi$ and $2 \pi$ of the resonance of the res_aux stage, for the continuity and energy recovery from the inductor $\mathrm{L}_{r_{-} \text {aux }}$ back to the capacitor $\mathrm{C}_{\mathrm{r}_{-} \text {aux }}$.

\section{III.SIMULATION RESULTS}

The circuit of Fig. 2, with eight stages, was simulated using PSpice software. The parameters were $V_{\mathrm{dc}}=1000 \mathrm{~V}$, $4.5 \mu \mathrm{F}$ capacitors $\mathrm{C}_{\mathrm{r}}, \mathrm{C}_{\mathrm{i}}$ and $\mathrm{C}_{\mathrm{r}_{\mathrm{a}} \text { aux }}, 8 \mathrm{mH}$ inductors $\mathrm{L}_{\mathrm{r}}$ and $\mathrm{L}_{\mathrm{r} \_a u x}$, operating with $50 \mathrm{~Hz}$ pulse repetition rate, to generate $6 \mathrm{kV}$ bipolar pulses, with $100 \mu \mathrm{s}$ pulse width, and $9.5 \mathrm{~ms}$ relaxation time (i.e. time between negative and positive pulses) into a resistive load.

Fig. 4 shows the simulated results for the load voltage $v_{0}$ with $\sim 17 \%$ voltage droop at the end of the negative and positive pulses.

Fig. 5 shows the simulated results for the voltage waveforms in capacitors $\mathrm{C}_{\mathrm{r}}$ and $\mathrm{C}_{\mathrm{r} \_ \text {aux }}$, and for the current 


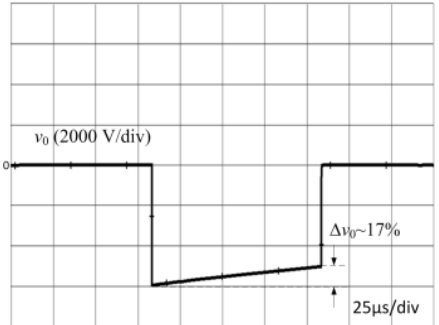

(a)

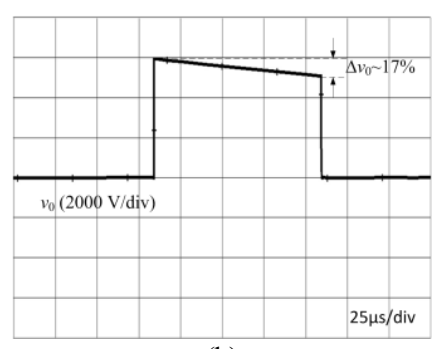

(b)

Figure 4. Simulation results for the output voltage of the circuit of Fig. 2 into a resistive load, without compensation and $\sim 17 \%$ voltage droop at the end of the negative (a) and positive (b) pulse. The scales are 25 $\mu \mathrm{s} /$ div (horizontal) and $2000 \mathrm{~V} /$ div (vertical).

waveforms in inductors $\mathrm{L}_{\mathrm{r}}$ and $\mathrm{L}_{\mathrm{r}-\text { aux }}$ and the load voltage $v_{0}$, with compensation. The positive and negative pulses

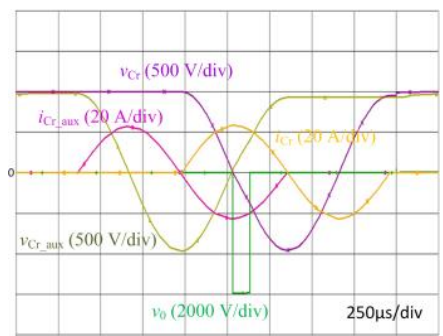

(a)

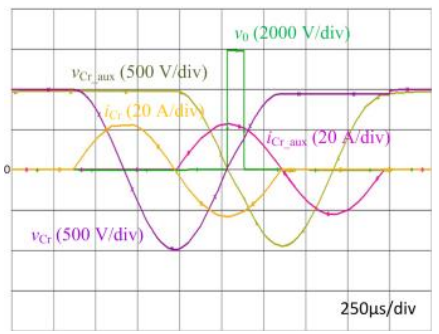

(b)

Figure 5. Simulation results for the capacitors $C_{r}$ and $\mathrm{C}_{\mathrm{r}_{-} \text {res }}$ voltages, $v_{\mathrm{Cr}}$ and $v_{\mathrm{Cr}_{-} \text {res }}$, current in inductors $\mathrm{L}_{\mathrm{r}}$ and $\mathrm{L}_{r_{-} \text {res }}, i_{\mathrm{Lr}}$ and $i_{\mathrm{Lr} r_{\text {res }}}$, and the output voltage, $v_{0}$, of the circuit of Fig. 2, with compensation from both stages, for negative (a) and positive (b) pulse. The scales are 250 $\mu \mathrm{s} /$ div (horizontal) and $500 \mathrm{~V} / \mathrm{div}$ (vertical) and 2000 V/div (vertical). occur at zero resonant voltage of the capacitors $C_{r}$ and $\mathrm{C}_{\mathrm{r}_{-} \text {aux }}$. For the negative or positive pulse, the resonance of the compensation stages res or res_aux, starts $t$ time (Eq. (1)) after the beginning of the resonance of the res_aux or res droop compensations stages, respectively.

Fig. 6 a) and b) show the simulation results of the output negative and positive pulse voltage with voltage droop compensation using a zoomed horizontal scale.

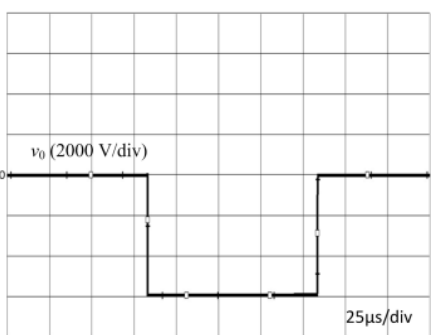

(a)

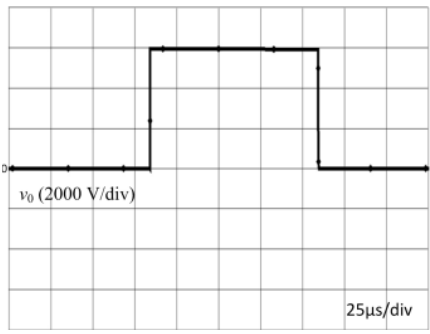

(b)

Figure 6. Simulation results of the obtained output (a) negative and (b) positive pulse voltage with dual resonant compensation with zoomed horizontal scale, $25 \mu \mathrm{s} / \mathrm{div}$ (horizontal) and 2000V/div (vertical).

\section{IV.SUMMARY}

A new design method to increase the range of the voltage droop compensation in generalized solid-state bipolar Marx generators, based on resonant circuits, for high-voltage repetitive pulsed power applications, is proposed.

Keeping the topology of the Marx circuit, one extra auxiliary stage with inductor was added to the existing Marx stages, to increase the range of the positive and negative output pulses voltage droop compensation.

The simulation results show that the resonant based voltage droop compensation stages together can compensate $17 \%$ voltage droop of the negative and positive pulse shape when the circuit operates with 8 stages Marx circuit with $50 \mathrm{~Hz}$ bipolar pulse repetition rate and using $1 \mathrm{kV}$ per stage. 


\section{REFERENCES}

[1] A. Haddad, D. Warne, Advances in High Voltage Engineering, IET Power and Energy Series 40, Institution of Engineering and Technology, London, United Kingdom, 2007, chapter 13, pp. 591-631.

[2] L. M. Redondo, J. Fernando Silva, Repetitive HighVoltage Solid-State Marx Modulator Design for Various Load Conditions, IEEE Transactions on Plasma Science, Vol. 37, No. 8, Part: 2, pp 1632-1637, 2009.

[3] Cassel, R.L.: "Pulsed Voltage Droop Compensation for Solid State Marx Modulator", in Proceedings of the IEEE International Power Modulators and High Voltage Conference, May 2008, pp. 117 - 119.

[4] Tang, Tao; Burkhart, Craig P.; Nguyen, Minh N.: “A vernier regulator for ILC Marx droop compensation", in IEEE Pulsed Power Conference, pp. 1402-1405, June 2009.

[5] Kim, J. H.; Jeong, I. W.; Ryoo, Hong-Je J.; Shenderey, Sergey V.; Kim, J. S.; Rim, G. H.: "Semiconductor switch-based fast high-voltage pulse generators", in 14th IEEE International Pulsed Power Conference, pp. 665-668, June 2003.

[6] Cassel, R. L.: "An All Solid State Pulsed Marx Type Modulator for Magnetrons and Klystrons", IEEE Pulsed Power Conference, pp. 836-838, 2005.

[7] L. M. Redondo, J. Fernando Silva, P. Tavares and E. Margato, "All Silicon Marx-bank topology for highvoltage, high-frequency rectangular pulses," in Proceedings of the 2005 IEEE 36th Annual Power Electronics Specialists Conference, 12-16 June, 2005, Recife, Brasil, pp. 1170-1174.

[8] Hiren Canacsinh, Luís M. Redondo, J. Fernando Silva, Beatriz Borges: "Voltage Droop Compensation Based on Resonant Circuit for Generalized High Voltage SolidState Marx Modulator", in IEEE Applied Power Electronics Conference and Exposition (APEC), Long Beach, California, USA, 20-24 March, 2016.

[9] Hiren Canacsinh; L. M. Redondo; J. Fernando Silva: "New Solid-State Marx Topology for Bipolar Repetitive High-Voltage Pulses", in 39th IEEE Power Electronics Specialists Conference, Greece, June 2008.

[10] L. M. Redondo; H. Canacsinh; J. Fernando Silva: "Generalized Solid-state Marx Modulator Topology", in IEEE Transactions on Dielectrics and Electrical Insulation, Vol. 16, No. 4, 2009, pp. 1037-1042. 